\title{
Chapter 3 \\ Workload Planning Management of Maintenance Activities in Nuclear Power Plants: Compensation Mechanisms at the Contractor Interface
}

\author{
Nicolas Dechy and Alexandre Largier
}

\begin{abstract}
By reviewing data from a normal operations safety assessment conducted by IRSN on nuclear safety management, we study some factors that impact the management of maintenance activities. We focus on practices, their benefits and limits, especially in the case of drifts that lead to compensation mechanisms observed at the contractor interface when dealing with workload planning.
\end{abstract}

Keywords Workload $\cdot$ Planning $\cdot$ Maintenance $\cdot$ Contractor $\cdot$ Safety

\subsection{Introduction}

Several accident investigations and research studies have highlighted the possible adverse effects of contracting. The general trend of "core business" refocusing and frequent organisational changes raises recurring concerns about management and governance of such risks. The contracting issue often becomes societal and controversial, with trade unions and NGOs highlighting transfers of responsibility for risky activities. However, the safety debate cannot be reduced to being for or against contracting. Moreover, the many forms contracting can take invite discussion about contracting in the plural [17]. In order to enhance organisational safety, the challenge is to study the conditions, practices and influencing factors that are required to obtain safe performance from industrial processes and prevent accidents.

Our goal is to describe and analyse some practices, either positive or negative, to organise maintenance work at the contracting interface. They are inferred from a normal operations case study, looking at day-to-day practices that may or may not be safe enough. Evidence is collected from a safety assessment that Institut de Radioprotection et de Sûreté Nucléaire (IRSN) performed on French nuclear power plant (NPP) maintenance outages and contracting management; these kinds of assessments are dedicated to providing evidence for safety regulation [13].

\footnotetext{
N. Dechy $(\varangle) \cdot$ A. Largier

Institut de Radioprotection et de Sûreté Nucléaire (IRSN), Fontenay-aux-Roses, France

e-mail: nicolas.dechy@irsn.fr
} 
The analysis will look at the provisions made by the nuclear operator and contractors for workload planning, the practices, their benefits and limits. It will highlight the limits of anticipation for workload planning, the adaptation mechanisms to compensate for drifts and their side effects. The discussion will address the effects of the contractor interface on anticipation and adaptation mechanisms.

\subsection{Maintenance Workload Planning at the Contractor Interface}

In the safety literature, there are several ways to study and produce knowledge on organisational reliability, resilience and safety in high-risk industries. Some researchers advocate the study of normal operations [1, 12], rather than the study of accidents, failures and vulnerability [16]. They have been seeking factors, practices and "best ways" of particular relevance for explaining how success is obtained in adverse conditions, highlighting features of organisational reliability, resilience and safety. These performance levels emerge from, and are embedded in, the day-to-day work practices of a long chain of actors inside and outside of an organisation, which all have a history. The many goals that an organisation pursues lead to tensions and dilemmas, which require compromises that are always contingent. Also, when investigating practices, it seems reasonable to take an approach looking at positive and negative effects [14]. This is even more relevant for maintenance, with its dual effects on safety.

\subsubsection{Anticipation and Adaptation}

Many influencing factors impact maintenance performance [10]; here, we focus only on one of them-the workload planning activity. The workload planning activity involves finding a balance between requests for maintenance tasks within a time window and deadline, and the availability of human resources. In the context of a scheduled outage for maintenance of an NPP (see Sect. 3.3), the workload related to maintenance activities dramatically increases, which makes this process even more critical to outage performance. The time dimension remains key for planning maintenance work, and planning is related to production pressures which impacts available human resources and maintenance working conditions. Workload planning is a process which closely interacts with programming, preparing, scheduling and resource management. To us, it is less tangible than scheduling [20] and seems to have received less attention in the safety literature.

Though planning is a key feature of management, reliability, safety and resilience, its ordinariness may lead to a lack of attention or interest [20]. In fact, this key coordination process is rather complex, integrating several dimensions, actors, and 
purposes [19]: prescribing, anticipating, coordinating, managing, warning, exploring, verifying, reporting, legitimising, justifying and making official information. It is dynamic with regards to information flows and performance feedback. It can be "tightly coupled" [16] and lead to a roll-on effect [3] when a small delay can lead to a bigger slip, as observed on the NASA space shuttle flight and maintenance management program.

Moreover, in contrast to standardised chain production, maintenance outages face high rates of unexpected events, variability and uncertainty [6]. When uncertainty is high, planning can drift [11] to a "fantasy plan" [2].

High-reliability organising calls for the management of tensions and contradictions between high levels of planning and rule-making, and adaptation to the unexpected through improvisation [21]. The anticipation-adaptation/resilience combination has been regularly addressed $[1,12,21]$. A key contributor to adaptation and resilience is "organisational slack" [5], summarised as an excess of resources.

However, a practical and theoretical issue arises from the recurring gap between planned and observed workload, at the end of the outage in our case. Actors have already experienced failures of foresight and delays in previous outages, so what should they do to better anticipate, or adapt and compensate when they occur? As this is not only a performance problem but also a safety concern, how is safety considered in workload planning?

\subsubsection{Effects of Contracting}

Maintenance workload planning is highly dependent on the reliability of the information exchanged at the contractor interface. The question we add here is transverse to the previous questions: how much does the contracting interface impact processes of anticipation and adaptation for workload planning?

Coordination and cooperation processes involve interfaces and boundaries between actors and stakeholders creating a "space in between" e.g. [18]. Some accidents highlighted [7, 8]: communication barriers (e.g. Challenger launch), less frequent and shorter interactions, formalisation of relationships, cultural gaps, transfer of responsibilities, and lack of sharing of lessons learned. All these factors could lead to a more fragmented and virtual organisation, with more diverging interests. Contracting companies challenged that contracting was the weak point of the supply chain only adding risks, highlighting that they also added benefits [4].

Workload planning is the responsibility of the contractor, who is required to perform a service with a result. Under European law, the nuclear operator cannot explicitly require a number of workers to be available when it pays a fixed price. Accordingly, the contractor does not have to disclose its resource plans. A research paper [9] on NPP maintenance outages highlighted how much the involvement of the contractor was different from the customer's when negotiating deadlines at the business level. In addition, when schedule delays occur, four different kinds of decisions lead to a consumption of the workers' time: the decision to use their workforce, 
to put them on standby for a waiting period, to ask them to work overtime and to modify their working week [9].

\subsection{Research Context, Method and Data}

Maintenance of NPPs is a complex activity. There are thousands of equipment items. Scheduled outages for maintenance activities occur approximately annually and typically extend over several weeks, allowing 3-15,000 activities to be completed and mobilising hundreds of nuclear operator workers, as well as hundreds of contractors in dozens of contracting and subcontracting companies.

To manage these maintenance activities, two key management processes are implemented by the nuclear operator: outage and contracting management. Outage management is ensured by a project management team of around 50 nuclear operator actors, mainly coming from maintenance and operation departments, dedicated for six months to a year. These actors are in charge of the preparation, execution and coordination of the activities planned for the outage. In France, around 400 companies involving more than 22,000 workers help to maintain the fleet of 58 reactors, with around 50 outages per year. Ten thousand workers out of the 23,000 employed by the French nuclear operator manage maintenance activities. The contractors must be certified as competent and financially sound by the nuclear operator to compete for contracts. Maintenance of NPPs is a regulated activity.

To describe the set of maintenance workload planning-related practices implemented by both the nuclear operator and contractors, especially those related to anticipation, adaptation and compensation when drifts and unexpected events occur, we used the data reported to the French nuclear safety authority (ASN) in the IRSN report [13] on assessment of management of safety of activities contracted by the nuclear licensee. This assessment relied on 50 days of field observations, 150 interviews on three 2013 and 2014 outages in three NPPs and the review of hundreds of documents. It required several person-years of effort over two to three years by eight human and organisational factors (HOF) specialists and their supervisors, in which we were involved as specialists.

\subsection{Findings and Analysis}

\subsubsection{Preparing for Maintenance Outages}

Workload planning depends on previous outage preparation activities, but also on feedback from later activities, and on the contracting process. Specifically, the list of activities to be performed, called the maintenance program, can be defined up to ten years in advance and is updated regularly and "frozen" six months before the outage 
to facilitate the preparation of thousands of activities on a stable basis. It also aims at giving contractors some visibility of the workload and type of activities that will be contracted. During the last months of preparation, it is updated every week and during the outage every day, in both cases to integrate new demands (e.g. unexpected equipment deficiency).

The principle of the outage process is "to integrate contractors as early as possible during preparation". The nuclear operator has developed contracts that last five years (extending to six or seven) to enable contractors to invest in and secure their technical and human resources in the long term, based on a promise of a minimum level of workload. A four-month milestone before the outage for signing contracts and work orders has been established as a rule for years. On this basis, resource planning can start with the skills required and the number of working hours needed per activity. Workload planning then depends on the more detailed schedules to be established later in the last months of outage preparation, when the working windows are established.

As of 2013, the French nuclear operator had experience of more than 1500 outages for its 58 reactors since the 1980s. So, most management rules and good practices are known and formalised and should "secure" anticipation of workload and visibility for contractors.

\subsubsection{Implementation of Provisions Related to Workload Planning}

Evidence shows that the nuclear operator does not always comply with its own milestones and rules. The freezing of the program six months before the outage is not respected. At one site, a technician in charge of valve maintenance described that ten days before the outage, he already knew that activity levels had risen and the workforce would be insufficient, but he did not communicate this to the contractor, instead proceeding as if the plan was still viable. On another site, it was reported that the practice is different, and contractors are advised when planned work changes so that they can adjust their workforce accordingly. When contractors are advised of changes before the four-month milestone, this may not be formalised. A valve maintenance contractor manager reported that he was notified informally of a volume upgrade but that work orders to formalise the change were not signed.

IRSN [13] noticed some progress compared to 2012 outages: the added maintenance activities dropped from $50 \%$ to between 15 and $20 \%$ in the six-month period before the outage, and from 50 to $30 \%$ during the outage. In the valve maintenance market, there is a chronic underestimation of volumes; at the end of the year, $25 \%$ to $40 \%$ more is done. The first reason is that the estimated volume of working hours is based on the most efficient contractor. Also, the 58-reactor nuclear fleet does not contract for all the volume but aims to keep some margins to allocate more work to the best contractors. In addition, as explained by a business manager in the valve 
maintenance market, the nuclear licensee corrects initial underestimated plans when (four-month milestone) they sign orders but it still underestimates the unplanned maintenance work. In the end, the final number of hours is as much as three times the estimate at the four-month mark.

With such enormous variations, late provision of final scope details hampers workload planning. A contractor manager claims at a meeting to have received only $8 \%$ of the documents of the programmed activities four months before the outage because of delays from the 2013 outages that impact the 2014 outages. Another contractor manager reports that documents for only $50 \%$ of maintenance activities were received at the beginning of the outage, which compromised workload spreading. The result is that contractors lose their trust in the schedule due to unplanned increases in activity, constantly changing priorities and the sense that everything is urgent.

\subsubsection{Restoring the Workload-Resource Balance}

These difficulties are known and do receive organisational response. Several compensation practices were observed to restore anticipation in a reactive manner, with some using the levers of the contractual relationships. In the first practice, some late work orders are issued with contract amendment and additional contracts until the maintenance work starts. Requests may be vague, such as having more staffing than the work order for instance on some weekends. If they are formalised, work orders may lead to paying for the service even if there is no activity. If requests remain informal, the contractor may add staff but faces uncertainty.

The second practice involves the overbooking of resources: this would become common practice, though varying from NPP to NPP, and would allow the outage project managers to build up resource margins or slack to cope with the uncertainty of volumes and dates and the lack of visibility by minimising their consequences. The third practice is redeployment between outages and NPPs: some human resources planned for an outage are transferred to another outage at the same NPP or another NPP, which requires negotiations and decisions at a higher level between the nuclear operator fleet managers and the NPP directors. A weekly meeting has been set up for that some trade-offs could lead to an outage being "sacrificed". The fourth practice is the reallocation of resources between work orders: resources earmarked for other activities can be mobilised by contract amendment; however, when reallocated to another contract with a different scope, this implies insurance problems.

Last but not least, the nuclear operator established a system to pay for waiting hours of contractor workers and set up for each NPP a team in charge of recording waiting hours. The goal is to avoid false notification and to check that the contractor demonstrates it cannot redeploy its workers to other activities. 


\subsubsection{Contractor Adaptability}

The implementation of these compensation mechanisms has various effects. Though anticipation capacities are restored with reactive measures, this tends to rely on the adaptability of contractors and their willingness to take financial risks by organising to make additional resources available when they have no guarantee of compensation.

The first effect relating to the practice of overbooking of resources: contractors also overbook resources in order to create margins that will allow them to be responsive. However, in order for these reserves to retain their margin function, both the contractors and the outage project must conceal them from each other (e.g. delays in preparing operating documents not communicated to keep personnel on site). This withholding of information can degrade the mutual trust of the partners and the relationship can become a "game of bluff". When the service provider itself uses subcontractors, it may also want to maintain margins. There may thus be a cascading amplification of planning difficulties at each level of subcontracting. Notice that after Fukushima in France, a maximum of three levels of subcontracting became the new norm to reduce risk transfers along the organisational chain in response to criticisms from NGOs and trade unions on contracting side-effects.

The second effect is on the workers' time and flexibility of geographic location: contractors may have to reorganise the work of their teams, for instance, in staggered working hours and in overtime, but also make temporary changes of location, at extremely short notice. This may concern up to 15-20\% of activities, according to the nuclear operator. For a contractor manager, the worst case factor is the delays that lead to peak loads and staggered shifts. A contractor manager has difficulty motivating his staff because he has to ask them to make efforts (e.g. staying available over the weekend), which sometimes prove to be unrewarded because of schedule delays.

The third effect has a direct impact on safety with changes of team composition: contractor companies reassign staff to cope with peak workloads. These reassignments can sometimes be made without respecting the skills constraints of the people involved, defined during the preparation process and recorded in the site organisation charts. The fourth effect involving the use of additional resources from other subcontractors: temporary workers may also be mobilised, which may threaten the skills available.

\subsection{Discussion and Conclusion}

NPPs seek to optimise the availability of their contractors' resources to ensure that work is completed on time, to reduce lost production and to control costs. The evidence presented above indicates that it is largely the contractors who must regulate the dynamic balance between effort required and resources. Anticipation of workload can be thwarted by a deterioration in the conditions (e.g. outage delays of the previous 
year) under which these resources can be deployed. Several compensation practices are implemented on both sides in response to degraded conditions in order to reestablish a form of regulation. The compensation mechanisms link the provisions, the drifts, the compensation practices and the effects.

Firstly, these compensation mechanisms respond to the intrinsic limits of any planning in complex systems with high rates of unexpected events [6]. Thus, recognition of this reality would require a better characterisation of these occurrences (e.g. frequency, severity of unexpected events, etc.) and the development of adaptive capacity beyond "slack" [5]. The building of this resilience capability should rely on a critical analysis of the implementation of compensation mechanisms and practices that can have adverse impacts on safety, which are currently underestimated and therefore not adequately managed. The evidence provided here could foster the debate and analysis.

Secondly, the contractual relationships impact the anticipation and adaptation capabilities. This complicates and rigidifies this organisational interface, by adding financial and legal dimensions to this working relationship [7, 8]. Thus, it may lead to a focus on financial management of workload planning failures with compensation for waiting hours; but this narrow focus makes business partners lose sight of the side effects on individual and collective skills and working conditions which directly impact safety. Another influencing factor is the inherent limits of transparency efforts that are being made on both sides to remedy the overbooking of resources. It is in each party's interest to retain room for manoeuvre, whether for anticipation or adaptation. These limits on transparency can affect the relationship of trust at each level of subcontracting and lead to a "game of bluff" that increases the risk of "fantasy planning" [2]. Thus, this contractual dimension increases the distance in the interstitial space of interfaces and makes this interstitial space more sensitive [18]. In these deteriorated working conditions, the workload planning and spreading become rather fuzzy.

Thirdly, these compensation practices, which call for adaptive capacities from contractors, are a source of tension and risks in some cases, which are increased by the asymmetric contractual relationship. Indeed, the contractual requirement of strong mobilisation of the contractors' employees can have a negative impact on the skills mobilised during field operations: fatigue and tensions induced by changes in working hours or location can reduce the vigilance of the workers; continuous changes in the schedule, with alternating high peak loads and waiting hours, generate demotivation and irritation, which can reduce the serenity and vigilance of workers; team recomposition can degrade collective and individual competence [15]; late provision of information to workers reduces their ability to prepare their work. The workers' individual time capital is the one that is negotiated and split by contractual stakeholders [9], and it is sometimes detrimental to the workers' well-being and safety. In such a case, the balance is not in favour of the contractor, which can lose the contract, or of the employee, who can lose his job.

Last of all, the asymmetrical contractual relationship is seen as a power asset for the customer. Failures tend to be attributed to the contractor, overshadowing the customer contribution that must provide adequate conditions. This situation generates 
a climate of blame that is detrimental to safety, as it blocks cooperation and learning. Both business partners should admit that successes and failures are their common responsibility.

Acknowledgements To our reviewers Sarah Fourgeaud, Franck Anner, Olivier Dubois (IRSN); Jan Hayes, Stéphanie Tillement.

Ethical Statement This work was approved by IRSN, the public institute that support the French nuclear safety authority. Data collection and reporting by IRSN experts is undertaken under a protocol that informs participants of the use of their testimonies and work observations after crossexamination, with anonymisation of interviewees and nuclear power plants.

\section{References}

1. M. Bourrier, The legacy of the high reliability organization project. J. Contingencies Crisis Manage. 19(1), 9-13 (2011)

2. L. Clarke, Mission Improbable: Using Fantasy Documents to Tame Disaster (University of Chicago Press, Chicago, 1999)

3. C.A.I.B., Columbia Accident Investigation Board Report, vol. 1. (National Aeronautics and Space Administration and the Government Printing Office, Washington, DC, 2003)

4. Comité sur les Facteurs Sociaux, Organisationnels et Humains (COFSOH), Pour une Contribution Positive de la Maintenance Sous-traitée à la Sûreté Nucléaire (2017)

5. R. Cyert, J. March, Organizational factors in the theory of oligopoly. Q. J. Econ. 70(1), 44-64 (1956)

6. N. Dechy, S. Thellier, J.-M. Rousseau, J. Pansier, F. Jeffroy, Management of unexpected situations during maintenance activities: controlling risks despite uncertainty, in Proceedings of the $\lambda \mu 19$ Conference (Institut pour la Maîtrise des risques (IMdR), Dijon, France, 21-23 Oct 2014)

7. Y. Dien, N. Dechy, Process safety of virtual organisations, in Proceedings of $\lambda \mu 18$ Conference (Institut pour la Maîtrise des risques (IMdR), Tours, France, 16-18 Oct 2012)

8. Y. Dien, N. Dechy, Les risques organisationnels des organisations fragmentées, in Proceedings of Les Entretiens du Risque (Institut pour la Maîtrise des risques (IMdR), Paris, France, 26-27 Nov 2013)

9. T. Globokar, Compromis temporels dans la gestion des projets. Le cas de la maintenance nucléaire. Revue Française de Gestion 2004/5 152, 81-96 (2004)

10. C. Grusenmeyer, Maintenance: organizational modes, activities and health and safety. Use of a French national survey and in-situ analyses. Accid. Anal. Prev. 73, 187-199 (2014)

11. J. Hayes, A. Hopkins, Nightmare Pipeline Failures: Fantasy Planning, Black Swans and Integrity Management (CCH, Sydney, 2014)

12. E. Hollnagel, D.D. Woods, N.C. Leveson (eds.), Resilience Engineering: Concepts and Precepts (Ashgate, Aldershot, 2006)

13. IRSN, La Maîtrise des Activités Sous-traitées par EDF dans les Réacteurs à eau Pressurisée en Exploitation, Rapport pour la Réunion du GPR du 11 Février (2015)

14. B. Journé, Introduction, Chaire RESOH, Journée partenaires, Paris, France, 20 January 2015

15. A. Largier, C. Delgoulet, C. de la Garza, Quelle prise en compte des compétences collectives et distribuées dans la gestion des compétences professionnelles? PISTES 10-1 (2008)

16. C. Perrow, Normal Accidents, Living with High Risk Technologies (Princeton University Press, New Jersey, 1984)

17. M. Ponnet, Thèse de Doctorat, Les relations de sous-traitance et leurs effets sur la sûreté et la sécurité dans deux entreprises: SNCF et GrDF, Université de Nantes (2011) 
18. K. Roberts, P. Madsen, V. Desai, The space between in space transportation: a relational analysis of the failure of STS-107, in Organization at the Limit (Blackwell Publishing, Malden, 2005)

19. S. Tillement, S. Gentil, Construction d'une performance industrielle sûre au sein de projets complexes, Chaire RESOH, Journée partenaires, Paris, France, 20 January 2015

20. S. Tillement, J. Hayes, Maintenance schedules as boundary objects for improved organizational reliability. Cogn. Technol. Work 21, 497-515 (2019)

21. K.E. Weick, K.M. Sutcliffe, Managing the Unexpected: Assuring High Performance in an Age of Complexity (Wiley, San Francisco, 2007)

Open Access This chapter is licensed under the terms of the Creative Commons Attribution 4.0 International License (http://creativecommons.org/licenses/by/4.0/), which permits use, sharing, adaptation, distribution and reproduction in any medium or format, as long as you give appropriate credit to the original author(s) and the source, provide a link to the Creative Commons license and indicate if changes were made.

The images or other third party material in this chapter are included in the chapter's Creative Commons license, unless indicated otherwise in a credit line to the material. If material is not included in the chapter's Creative Commons license and your intended use is not permitted by statutory regulation or exceeds the permitted use, you will need to obtain permission directly from the copyright holder.

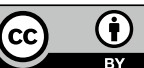

